\title{
Mandibular Precedence in the Prenatal Development of Four Permanent Teeth
}

\author{
ALPHONSE R. BURDI, STANLEY M. GARN AND \\ JEROME N. SUPERSTINE \\ Department of Anatomy and Center for Human Growth and Development, \\ The University of Michigan, Ann Arbor, Michigan 48104
}

KEY WORDS Dentition - Tooth formation - Embryology · Odontogenesis ' Sequence.

\begin{abstract}
As shown in 62 pairs of dental opponents from 32 grossly normal human fetuses in the $75-378 \mathrm{~mm}$ crown-rump range, mandibular precedence is the rule for $\mathrm{I} 1, \mathrm{I} 2, \mathrm{C}$ and $\mathrm{M1}$, a trend in agreement with mandibular precedence for deciduous teeth through $\mathrm{dm} 1$ and in the gingival emergence of the same permanent teeth during postnatal development.
\end{abstract}

In the course of development of 32 permanent teeth, dental opponents rarely emerge in synchrony. Rather there is a schedule of jaw precedence, such that the anterior teeth tend toward earlier emergence in the mandible while more posterior teeth may evidence maxillary precedence. This pattern of asynchrony in the emergence of dental opponents and with a patterned gradient of mandibular/maxillary precedence characterizes a variety of living populations (Israel et al., '67; Israel et al., '68). Such asynchrony and pattern of mandibular/maxillary precedence also characterizes the early development of the deciduous dentition, even below the $60 \mathrm{~mm}$ crown-rump length (Burdi et al., '70). The question necessarily arises, therefore, as to whether the pattern and the gradient of mandibular precedence in permanent tooth emergence also has prenatal origins or whether it is a strictly postnatal dental development.

To answer this particular question, we examined serial sagittal (i.e., vertical) jaw sections of 32 human fetuses in the 75-378 $\mathrm{mm}$ crown-rump range and gave attention to the maximum of four pairs of opponents that may show some degree of development in that size range. For $\mathrm{I} 1, \mathrm{I} 2, \mathrm{C}$ and $\mathrm{M} 1$ and in the maxilla or the mandible separately, each tooth was rated as to stage of development as previously described by us in detail (cf. Garn and Burdi, '71; Burdi et al., '74). The resulting data were then divided into (1) those cases where the mandibular tooth was advanced by one or more stages, (2) those cases where mandibular and maxillary opponents were equal in prenatal development, and (3) those cases where maxillary teeth were demonstrably advanced over their mandibular opponents. In all, 62 pairs of opponents were thus considered 21 pairs of central incisors, 16 pairs of lateral incisors, 5 pairs of canines and 20 pairs of first molars. Examples of mandibular and maxillary precedence are shown in the photomicrographs reproduced in figure 1.

As shown in table 1, then, mandibular precedence proved to be far more common than maxillary precedence for all 4 tooth classes considered (I1, I2, C and M1) and for 62 pairs of permanent tooth opponents. Of the total of 62 permanent tooth opponents studied in the $75-378 \mathrm{~mm}$ crownrump range, mandibular precedence was confirmed for 33 pairs, equal development was assessed for 20 pairs, while maxillary precedence was recorded for only 9 pairs of dental opponents. Further restricting the analysis to those pairs of permanent tooth opponents where developmental precedence was clear, the recalculated proportions of mandibular precedence were then $73 \%$ for $\mathrm{I} 1,78 \%$ for $\mathrm{I} 2,100 \%$ for $\mathrm{C}$ and $79 \%$ for M1. Again, employing only the pairs of opponents where development precedence was clear, the observed numbers were 33 for mandibular precedence as against 9 for maxillary precedence. Calculated against chance expectancy of $21.5: 21.5$, the sto- 

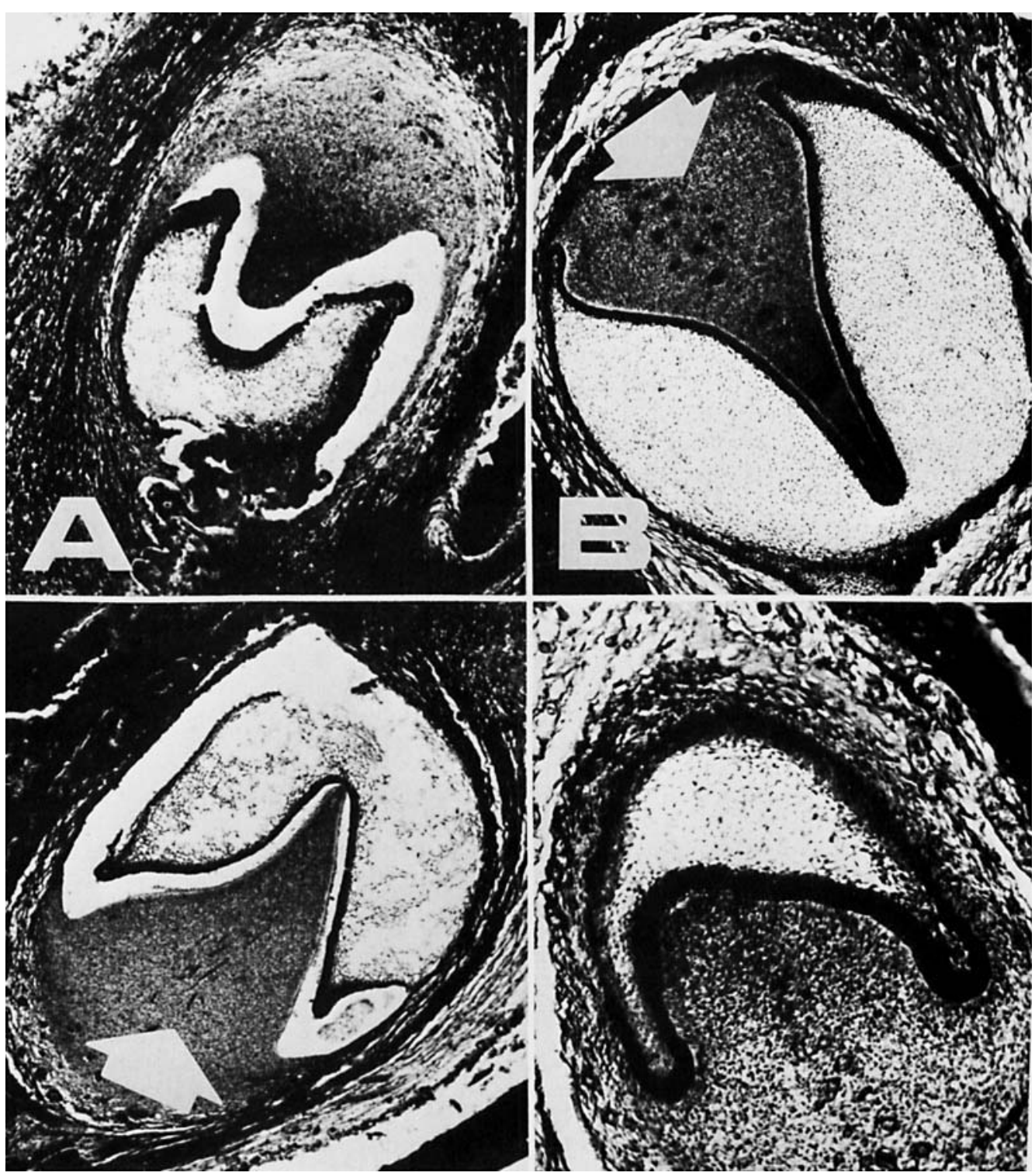

Fig. 1 Photomicrographs showing mandibular precedence (left) and maxillary precedence (right) in developing central incisors from two fetuses in the 330-350 crown-rump length range. The white arrows in each case point to the more advanced tooth of the pair of opponents showing greater mesenchymal differentiation, more advanced differentiation of ameloblasts and sharper demarcation between the inner enamel epithelium and the stellate reticulum. The photomicrographs are maintained such that the teeth in question indicate their relative relationships in the fetal jaws. 
TABLE 1

Mandibular vs maxillary precedence in early prenatal dental development

\begin{tabular}{lcccc}
\hline & & \multicolumn{3}{c}{ Percent with } \\
\cline { 3 - 5 } Tooth & $\begin{array}{c}\text { No, } \\
\text { of } \\
\text { jaws }\end{array}$ & $\begin{array}{c}\text { Mandibular } \\
\text { precedence }\end{array}$ & $\begin{array}{c}\text { Equal de- } \\
\text { velopment }\end{array}$ & $\begin{array}{c}\text { Maxillary } \\
\text { precedence }\end{array}$ \\
\hline I1 & 21 & 52.4 & 28.6 & 19.0 \\
I2 & 16 & 43.8 & 43.8 & 12.5 \\
C & 5 & 80.0 & 20.0 & 00.0 \\
M1 & 20 & 55.0 & 30.0 & 15.0 \\
\hline
\end{tabular}

Note that the canine is the last-forming of the four teeth here considered in the 11-week through term fetus.

chastic chi-squared was then 14.5 . These observed percentages were in the same order of direction we had earlier reported for various North American and South American Amerindian populations (Israel et al., '68). They are, moreover, in the direction, though not of the magnitudes we have separately ascertained, for over 3,000 preadolescent participants in the 10-State $\mathrm{Nu}$ trition Survey of 1968-1970. Finally, the observed percentages of mandibular precedence in this study compare well with our previous findings on the developing deciduous dentition in the $14-58 \mathrm{~mm}$ crownrump range, but excluding the deciduous second molar (Burdi et al., '70).

It would appear, therefore, that mandibular precedence in permanent tooth development in I1, I2, C and M1 is not restricted to the postnatal period (more specifically the fifth through the twelfth year) nor to the emergence of the permanent teeth through the gums (i.e., gingival emergence). Rather, mandibular precedence appears to be a characteristic of the developing dentition, both for the deciduous teeth in the 14-58 $\mathrm{mm}$ crown-rump range and for the first four permanent teeth in the 75-378 $\mathrm{mm}$ crown-rump range.

At the same time, attention should also be given to the minority of individuals in both the early fetal period and the later period as well as in postnatal time, who evidence maxillary rather than mandibular precedence. In the present study, involving fetuses in the 75-378 $\mathrm{mm}$ crown-rump range and in our earlier studies of prenatal deciduous tooth formation as well as in our earlier studies of permanent tooth emergence, there is a small proportion of in- dividuals in whom maxillary precedence characterizes several pairs of opponents, simultaneously.

Naturally, we do not assume that a 200 mm human fetus evidencing mandibular or maxillary developmental precedence for a given pair of permanent tooth opponents would have evidenced exactly the same emergence sequence 6 to 12 years later. Even during postnatal dental development individuals may evidence changes in the relative level of formation of pairs of permanent teeth (Garn and Lewis, '57). At the same time, the general trend toward mandibular precedence for I1, I2, C and M1 in the $75-378 \mathrm{~mm}$ fetus, coupled with the existence of specific sequence polymorphisms in fetal time, does suggest the possibility that relative mandibular/maxillary precedence is established very early in human development for the permanent and the deciduous dentition alike.

\section{ACKNOWLEDGMENTS}

The work described in this paper was carried out under the grant DE 03443 from the National Institute of Dental Research.

We wish to express our appreciation to Dr. James K. Avery for the availability of fetal material, the assistance of Paul Schelble in preparing the photomicrographs, and that of Dixie Farquharson in completing the manuscript.

\section{LITERATURE CITED}

Burdi, A. R., S. M. Garn and W. J. Babler 1974 Greater female communalities in prenatal hand and dental development. Archs. Oral Biol., 19: $461-465$.

Burdi, A. R., S. M. Garn and R. L. Miller 1970 Mesiodistal gradient of mandibular precedence in the developing dentition. J. Dent. Res., 49: 889.

Garn, S. M., and A. R. Burdi 1971 prenatal ordering and postnatal sequence in dental development. J. Dent. Res., 50: 1407-1414.

Garn, S. M., and A. B. Lewis 1957 Relationship between the sequence of the calcification and the sequence of eruption of the mandibular molar and premolar teeth. J. Dent. Res., 36: 992-995.

Israel, H., A. A. Dahlberg, S. M. Garn and R. S Kerewsky 1967 Relative eruption precedence of mandibular and maxillary teeth in two populations. J. Dent. Res., 47: 456.

Israel, H., R. Fierro Benitez and S. M. Garn 1968 Eruption sequence polymorphisms of maxillary and mandibular opponents in the dentition of Quechua Indians of Ecuador. Archs. Oral Biol., 13: 239-241. 